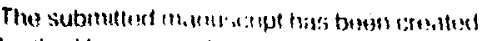
by tho Univensity al (iluciago as Opurtito of Argonne? Nillom.l 1 iboralory ("Argommo") under Contrint No W 31 109 ENG 38 will the U.S Departunesn of Energy. The US. Government retants for itsoll, and others ict ing on its bethall. a paid up. nonexclusive. irrevocable worldwide hicense in said article to reproduce. prepare derivative works. dis tribute copies to the public, and perform pub. licly and display publicly. by or on behalf of the Government.

\title{
Coherent Multimoded Dielectric Wakefield Accelerators
}

\author{
J. Power, W. Gai and P. Schoessow \\ Argonne National Laboratory, High Energy Physics Division \\ 9700 S Cass Ave, Argonne IL 60439
}

\begin{abstract}
There has recently been a study of the potential uses of multimode dielectric structures for wakefield acceleration [1]. This technique is based on adjusting the wakefield modes of the structure to constructively interfere at certain delays with respect to the drive bunch, thus providing an accelerating gradient enhancement over single mode devices. In this report we examine and attempt to clarify the issues raised by this work in the light of the present state of the art in wakefield acceleration.
\end{abstract}

\section{INTRODUCTION}

The utility of dielectric loaded structures as wakefield accelerators has been investigated for the past decade [2-4]. Some progress has been made towards demonstrating the feasibility of this technique $[5,6]$.

Previous work on dielectric devices has in general assumed that only a single $\mathrm{TM}_{01}$ accelerating mode is present in the structure. Recently, a new scheme of wakefield acceleration using a dielectric loaded waveguide which makes use of many $\mathrm{TM}_{0_{n}}$ modes excited by a drive bunch train to enhance the accelerating gradient [1]. The structure is cleverly designed so that the coherent sum of the modes Fourier synthesizes a longitudinal wake which on the axis of the structure approximates a train of alternating sign delta functions.

In this report, we examine this interesting scheme, considering only the longitudinal wakefields. We attempt to clarify some of the confusion in terminology which has arisen from this work.

\section{WAKEFIELDS IN DIELECTRIC LOADED WAVEGUIDES}

Consider a dielectric channel with an axial vacuum channel and conductor on the exterior. The dielectric channel has inner radius $a$ and outer radius $b$ with dielectric constant $\epsilon$. When a single charged particle beam (rms pulse length $\sigma_{z}$

Submitted to the proceedings of the 8 th Workshop on Advanced Accelerator Concepts (AAC'98), Baltimore, MD, July 5-11, 1998. 


\section{DISCLAIMER}

This report was prepared as an account of work sponsored by an agency of the United States Government. Neither the United States Government nor any agency thereof, nor any of their employees, make any warranty, express or implied, or assumes any legal liability or responsibility for the accuracy, completeness, or usefulness of any information, apparatus, product, or process disclosed, or represents that its use would not infringe privately owned rights. Reference herein to any specific commercial product, process, or service by trade name, trademark, manufacturer, or otherwise does not necessarily constitute or imply its endorsement, recommendation, or favoring by the United States Government or any agency thereof. The views and opinions of authors expressed herein do not necessarily state or reflect those of the United States Government or any agency thereof. 


\section{DISCLAIMER}

Portions of this document may be illegible in electronic image products. Images are produced from the best available original document. 


\section{NUMERICAL EXAMPLES}

In this section we will show some examples of wakefields in multimoded structures. The wakes are calculated using the analytic approach of reference [3]. The transcendental equation obtained for the dispersion relation is solved numerically for each mode and the mode amplitude $W_{z n}(a, b, \epsilon)$ is evaluated. The modes are then summed to obtain the wake potential according to Equation 3.

We first calculate the wakefield in a $\lambda=21 \mathrm{~cm}$ device designed by Hirshfield as a multimode device. This is a circular dielectric waveguide with $a=0.15 \mathrm{~cm}, b=$ $1.97 \mathrm{~cm}, L=60 \mathrm{~cm}$, and $\epsilon=9.43$. The wake potential for a $\sigma_{z}=0.1 \mathrm{~cm}$ bunch (including the region inside the beam) is shown in figure 1. The transformer ratio $R=2.384 / 1.307=1.824<2$.

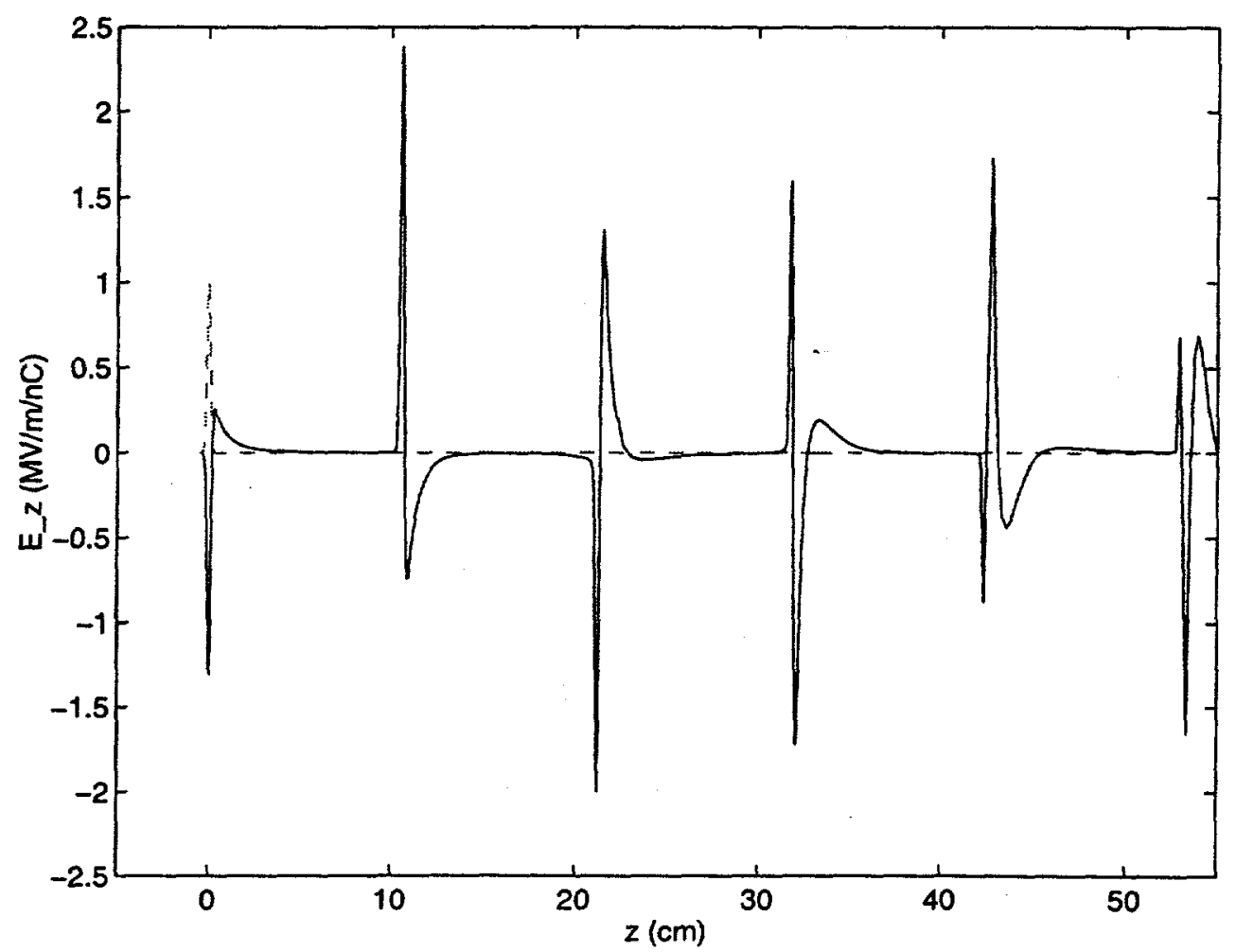

FIGURE 1. Wake potential for multimode $21 \mathrm{~cm}$ wavelength structure. The dashed curve shows the beam charge distribution.

Figures 2 shows the mode spectrum for this structure weighted by the current form factor (Fourier transform of $f(z)$ ) for 200 modes. It is interesting to note that in contrast to most structures considered for wakefield accelerators, the lowest lying modes do not dominate the spectrum.

Another aspect of the work in reference [1] is the suggestion that driving a multimode structure with a train of periodically spaced bunches would allow stimulated 


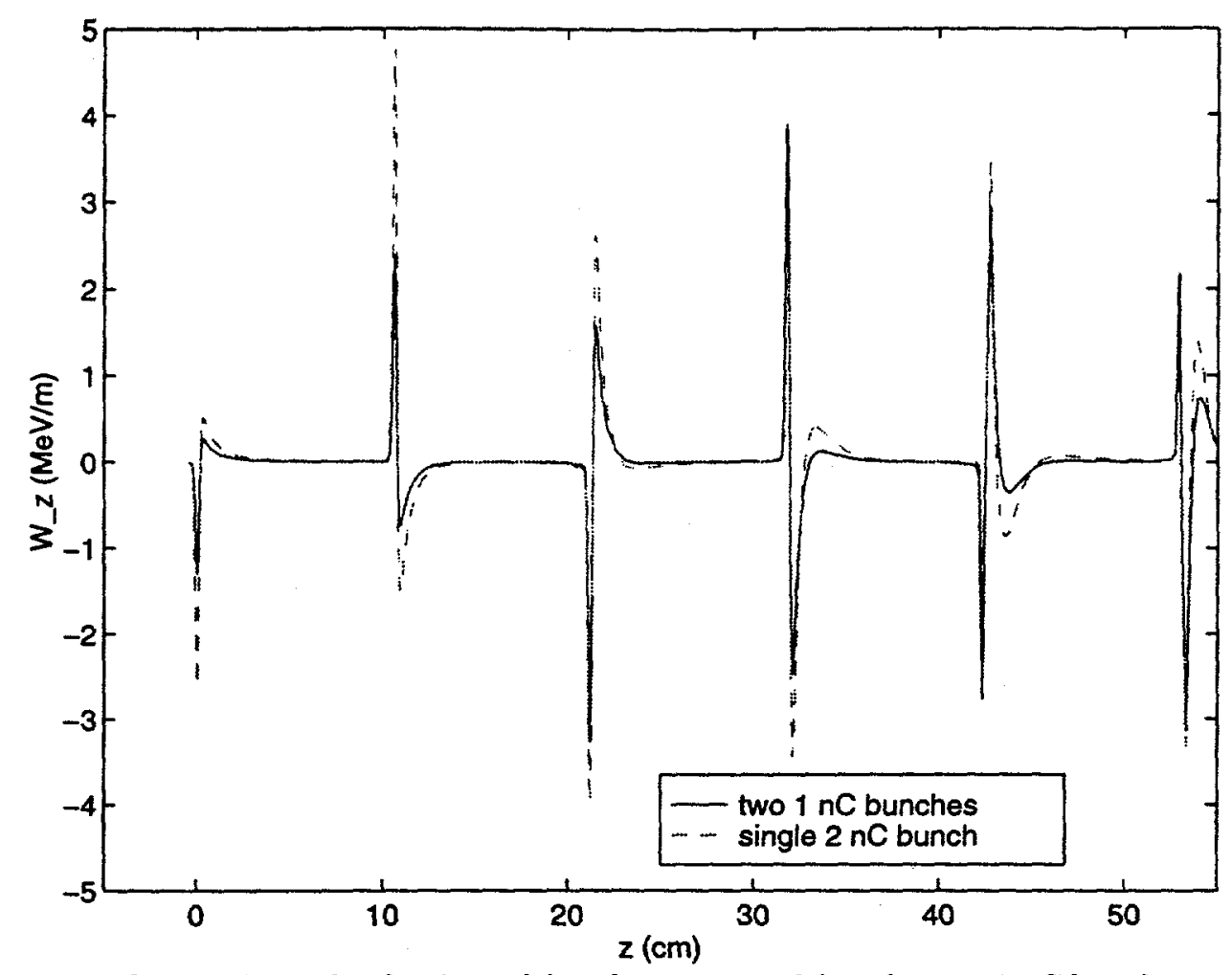

FIGURE 3. Comparison of wakes in multimode structure driven by two $1 \mathrm{nC}$ bunches separated by $21 \mathrm{~cm}$ vs wake driven by a single $2 \mathrm{nC}$ bunch.

theorem still holds, even though our numerical calculations agree with reference [1]. We also found the wakefield enhancement due to the use of multiple drive bunches simply scales with the total charge if one assumes all the beam parameters are the same for the individual bunches in the train. However, we believe that the multiple drive bunch scheme has an advantage considering both the capabilities of $\mathrm{rf}$ photocathode electron sources to produce bunch trains and the reduced sensitivity of multiple beams to parasitic wakefields in dielectric structures. We have designed an experiment at AWA to demonstrate this technique.

\section{ACKNOWLEDGEMENTS}

We would like to thank J. Hirshfield and T. Zhang for stimulating discussions in this area. This work is supported by the Department of Energy, Division of High Energy Physics, under contract W-31-109-ENG-38. 


\section{REFERENCES}

1. T-B. Zhang, J. L. Hirshfield, T. C. Marshall, B. Hafizi, Phys. Rev. E56 4647 (1997) J. L. Hirshfield et al., these Proceedings

2. R.Keinigs, M. Jones, W.Gai, Part. Accel. 24223 (1989)

3. M. Rosing, W. Gai, Phys. Rev. D42 1829 (1990)

4. W. Gai, P. Schoessow, B. Cole, R. Konecny, J. Norem, J. Rosenzweig, J. Simpson, Phys. Rev. Lett. 612756 (1988)

5. P. Schoessow, M. E. Conde, W. Gai, R. Konecny, J. Power, J. Simpson, to appear in J. Appl. Phys.

6. M. E. Conde, W. Gai, R. Konecny, J. Power, P. Schoessow, P. Zou, these Proceedings

7. K. Bane, P. Chen, P. Wilson, IEEE Trans. Nucl. Sci. NS-32 3524 (1985) 